\title{
UP TO DATE
}

\section{MODE OF ACTION OF THE MAIN}

ANTI-PARASITIC DRUGS

\section{Marina Clare Vinaud and Ruy de Souza Lino Junior}

\section{ABSTRACT}

\begin{abstract}
Neglected tropical diseases affect more than 1 billion people in tropical and subtropical regions most of them are caused by parasites. Several of these diseases already have effective drugs capable of eliminating the causative parasite, however are not capable of interrupting the transmission cycle. This fact induces the continuous of repetitive treatments, which may result in the parasite's resistance. This review aims to show the mechanism of action of the main drugs used to treat parasitic neglected tropical diseases in order to determine the drug's target and help the understanding of how the parasites are killed within the host.
\end{abstract}

KEY WORDS: Parasitic neglected tropical diseases; mode of action; drugs.

\section{INTRODUCTION}

Neglected tropical diseases (NTD) are transmissible diseases that prevail in tropical and subtropical regions affecting more than 1 billion people. Most of the infected individuals are living in poverty conditions without adequate sanitation, treated water and in close contact with vectors and domestic animals (WHO, 2017).

In spite of having effective anti-parasitic drugs against most of the NTD, their incidence is increasing worldwide especially due to its mode of transmission and its close relation to poor hygienic habits and degrading general condition of life (Andrews et al., 2014; Colley et al., 2014).

The mechanism of action of anti-parasitic drugs have been investigated because it can point to the drug's target whether biochemical or structural within the parasite. As the target is determined also resistance mechanisms are found which help to understand why certain parasites present an increasing incidence and how the host-parasite relationship is established (Bergquist et al., 2017; Genetu et al., 2017).

The drugs indicated by WHO to treat the most prevalent parasitic NTD's are described in Table 1.

This review aimed to describe the mode of action of the main drugs used to treat the most common parasitic NTD's found in the Americas.

Tropical Pathology and Public Health Institute, Federal University of Goias, Goiania, Brazil.

Corresponding author: Marina Clare Vinaud, Laboratory of studies of the host-parasite relationship, Tropical Pathology and Public Health Institute, Federal University of Goias. Rua 235, s/n, Setor Universitário, CEP 74605-050 Goiania, Goias, Brazil. E-mail: marinavinaud@gmail.com 
Table 1. Parasitic neglected tropical diseases, etiological agent, mode of transmission and main anti-parasitic drug used in its treatment.

\begin{tabular}{|c|c|c|c|}
\hline $\begin{array}{l}\text { Parasitic neglected } \\
\text { tropical disease }\end{array}$ & Etiological agent & Transmission & $\begin{array}{l}\text { Anti-parasitic } \\
\text { drug }\end{array}$ \\
\hline Chagas disease & Trypanosoma cruzi & $\begin{array}{l}\text { Vector borne - } \\
\text { insects of the } \\
\text { Triatominae } \\
\text { family; oral, blood } \\
\text { transfusion, vertical } \\
\text { transmission }\end{array}$ & $\begin{array}{l}\text { Benznidazole and } \\
\text { Nifurtimox }\end{array}$ \\
\hline Leishmaniasis & Leishmania $\mathrm{spp}$ & $\begin{array}{l}\text { Vector borne - flies } \\
\text { of the Phlebotomus } \\
\text { or Lutzomyia genus }\end{array}$ & $\begin{array}{l}\text { Pentavalent } \\
\text { antimonials } \\
\text { (sodium } \\
\text { stibogluconate), } \\
\text { miltefosine. } \\
\text { Others }\end{array}$ \\
\hline Taeniasis & $\begin{array}{l}\text { Taenia solium } \\
\text { Taenia saginata } \\
\text { Taenia asiática }\end{array}$ & $\begin{array}{l}\text { Food borne - } \\
\text { ingestion of raw or } \\
\text { undercooked meat } \\
\text { containing cysticerci }\end{array}$ & $\begin{array}{l}\text { Praziquantel, } \\
\text { Niclosamide, } \\
\text { Nitazoxanide }\end{array}$ \\
\hline Cysticercosis & Taenia solium & $\begin{array}{l}\text { Food borne - } \\
\text { ingestion of } \\
\text { water or raw food } \\
\text { contaminated with } \\
\text { eggs of the parasite }\end{array}$ & $\begin{array}{l}\text { Praziquantel and/ } \\
\text { or Albendazole }\end{array}$ \\
\hline Echinococcosis & $\begin{array}{l}\text { Echinococcus granulosus } \\
\text { Echinococcus multilocularis }\end{array}$ & $\begin{array}{l}\text { Food/water borne } \\
\text { - Ingestion of } \\
\text { parasite's eggs, dirty } \\
\text { hands disease }\end{array}$ & Albendazole \\
\hline $\begin{array}{l}\text { Foodborne } \\
\text { trematodiasis }\end{array}$ & $\begin{array}{l}\text { Clonorchis sinensis } \\
\text { Opistorchis viverrinin } \\
\text { Fasciola hepatica } \\
\text { Fasciola gigantica } \\
\text { Gnathostoma spinigerum }\end{array}$ & $\begin{array}{l}\text { Food borne-- } \\
\text { ingestion of } \\
\text { fish, vegetables, } \\
\text { crustaceans } \\
\text { contaminated with } \\
\text { larval parasites }\end{array}$ & $\begin{array}{l}\text { Clonorchiasis and } \\
\text { Opisthorchiasis - } \\
\text { Praziquantel; } \\
\text { Fascioliases - } \\
\text { Triclabendazole; } \\
\text { Gnathostomiasis } \\
\text { - Albendazole }\end{array}$ \\
\hline Schistosomiasis & $\begin{array}{l}\text { Schistosoma mansoni } \\
\text { Schistosoma haematobium } \\
\text { Schistosoma japonicum, } \\
\text { others }\end{array}$ & $\begin{array}{l}\text { Active skin } \\
\text { penetration of } \\
\text { cercariae released } \\
\text { from freshwater } \\
\text { snails }\end{array}$ & Praziquantel \\
\hline $\begin{array}{l}\text { Soil-transmitted } \\
\text { helminthiases }\end{array}$ & $\begin{array}{l}\text { Ascaris lumbricoides } \\
\text { Ancylostoma duodenale } \\
\text { Necator americanus } \\
\text { Trichuris trichiura }\end{array}$ & $\begin{array}{l}\text { Soil contaminated } \\
\text { with human faeces, } \\
\text { dirty hands diseases }\end{array}$ & $\begin{array}{l}\text { Albendazole or } \\
\text { mebendazole }\end{array}$ \\
\hline
\end{tabular}

Adapted from WHO, 2016; WHO, 2017; Aronson et al., 2016 
BZN (N-benzyl-2-(2-nitro-1H-imidazol-1-yl)acetamide) and NFX ((E)-N-(3-methyl-1,1-dioxo-1,4-thiazinan-4-yl)-1-(5-nitrofuran-2-yl) methanimine) belong to the nitroimidazole drug family therefore containing a nitro group linked to an imidazole ring (Trochine et al., 2014).

$\mathrm{BZN}$ is a pro-drug that requires activation within the parasite as to perform its activity. An unusual prokaryotic type I nitroreductase was identified in trypanosomatid parasites which is responsible for the reductive activation of BZN (Trochine et al., 2014), while the bioactivation of NFX is dependent on a type II nitroreductase (Patterson \& Wyllie, 2014).

Both BZN and NFX activities are related to their reduced nitrointermediates, which covalently modify and inactivate macromolecules such as lipids, DNA and proteins (Trochine et al., 2014). Also reactive oxygen species (ROS), generated by the interaction of reduced nitrointermediates with oxygen, lead to an intense intracellular oxidative stress and are particularly effective against $T$. cruzi because the parasite lacks catalases and is partially deficient in peroxidases (Docampo \& Moreno 1984). Additionally, nonenzymatic reactions with BZN intermediates generate glyoxal which is highly toxic and may contribute for the parasite's cell death in spite of the low velocity of this metabolite formation (Patterson \& Wyllie, 2014; Trochine et al., 2014).

Since BZN and NFX are mostly effective in the treatment of the acute phase of the infection, congenital transmission and children with chronic infection the search for new active compounds is paramount for the control of this disease (Paucar et al., 2016). Several studies have been performed as to determine new eligible targets within the parasite such as key metabolic enzymes: farnesyl pyrophosphate synthase, trans-sialidase, cruzipain (a cysteine protease), trypanothione reductase, glucose 6-phosphatedehydrogenase, glyceraldehyde 3-phosphate-dehydrogenase and alphahydroxy acid dehydrogenase (Rivera et al., 2009; Urbina, 2010). Inhibitors of de novo sterol biosynthesis are one of the most advanced strategies for the development on novel anti-T. cruzi agents as they block de novo production of alkyl-sterols which is an essential biochemical pathway for the parasite's survival and is not replaced by the host's cholesterol synthesis (Urbina, 2009). Some of these compounds are experimentally active against acute and chronic murine Chagas disease and against NFX and BZN-resistant strains. One of the advantages described in this approach is the selectivity and potency of the treatment, less side effects and better tolerability. On the other hand, the limitations are the cost and complexity to manufacture these compounds (Urbina, 2009). Antifungal drugs such as azoles in clinical use or undergoing clinical trials have been considered promising on in vitro and in vivo assays against $T$. cruzi. Some of these, such as posaconazole and a pro-drug of 
ravuconazole, are being evaluated in studies aiming Chagas disease treatment (Buckner \& Urbina, 2012).

The evaluation of other nitroheterocyclic drugs on acute and chronic phases (Francisco et al., 2016), natural compounds on in vitro analysis (Ebiloma et al., 2017) are approaches that may result in active compounds against the parasite.

Also the improvement of chemical characteristics of the drugs such as the enhancement of BZN and NFX dissolution rate (Fonseca-Berzal et al., 2015; Figueredo et al., 2017) may result in a better reach of the drug metabolites to the therapeutic targets within the parasite when it is in the amastigote form within the parasitophorous vacuole (Campo et al., 2016).

\section{Pentavalent antimonials (PA) - sodium stibogluconate}

Sodium stibogluconate (trisodium (3R,4S,5R)-1-\{[(3R,4S,5R)3-carboxylato-5-[(1R)-1,2-dihydroxyethyl]-1-oxido-2,6,7-trioxa-1stibabicyclo[2.2.1]heptan-1-yl]oxy\}-5-[(1R)-1,2-dihydroxyethyl]-1-hydroxy2,6,7-trioxa-1-stibabicyclo[2.2.1] heptane-3-carboxylate nonahydrate) is indicated in the treatment of leishmaniasis as an alternative to trivalent antimonials such as tartar emetic. It has been proposed that the drugs enter the parasitic cell via a phosphate transporter. Once inside the cell they induce the oxidation of thiols (glutathione, cysteine and cysteine-glycine) and inhibit trypanothione reductase (Wyllie et al., 2004). It is believed that PA needs to be reduced to the trivalent form as to be active, however it is not clear how this occurs inside the parasite as well as inside macrophages (Singh et al., 2012). Other studies suggest that after the activation of PA's there is a depletion of purine nucleosides (Frezard et al., 2009). On the other hand, after reduction of PA's to form trivalent antimonials there is a complexation with glutathione and other thiols which lead to a series of reactions that result in the apoptosis of the amastigote (Frezard et al., 2009). Other studies show that there is a 50\% decrease in the parasite DNA, RNA protein and purine nucleoside triphosphate levels added to the reduction in ATP and GTP synthesis leading to a decrease in macromolecular synthesis within the parasite which contributes to its death (Mukherjee et al., 2016). Specifically, sodium stibogluconate inhibits DNA topoisomerase I leading to the inhibition of DNA replication and transcription (Walker \& Saravia, 2004).

As PA are mostly effective against amastigotes which are the parasitic form inside macrophages it is highly recommended that drug trials even the ones selected from in silico platforms are performed in amastigote cultures and in animal experimental models (Andrews et al., 2014).

The development of liposomal and cyclodexitrin-based formulations may enhance the therapeutic activity of PA's as these formulations increased 
the reach of the active compound within the parasite's biochemical/molecular target (Frezard et al. 2009).

\section{Miltefosine}

Miltefosine (1-O-hexadecylphosphocholine) is used in the treatment of visceral leishmaniasis. Its mode of action is not entirely understood and the most reports and investigations regarding it have been made in promastigote assays (Aronson et al., 2016).

Its mode of action has been related to the impairment of the alkylphospholipid metabolism and the biosynthesis of alkyl-anchored glycolipids and glycoproteins. It has been reported that in L. donovani promastigotes miltefosine is capable of inducing an apoptosis-like death (Verma \& Dey, 2004; Paris et al., 2004). Several reports have described that miltefosine affects the lipid metabolism of promastigotes with emphasis on sterols and fatty acids oxidation (Rakotomanga et al., 2005; Rakotomanga et al., 2007). Studies have shown that miltefosine also impairs the calcium homeostasis leading to the cell death by apoptotic mechanisms. The calcium regulation is especially compromised in the mitochondrion membrane, endoplasmic reticulum and acidocalcisomes. This process results in a large increase in intracellular calcium concentrations inducing the parasite death (Serrano-Martin et al., 2009; Benaim \& Garcia, 2011). In combination with amiodarone, miltefosine is capable of inducing the cure of an experimental model of cutaneous leishmaniasis by $L$. mexicana through the disruption of the calcium homeostasis, inhibiting the proliferation of intracellular amastigotes (Serrano-Martin et al., 2009).

Metabolomics analyses have determined that miltefosine is capable of altering around $10 \%$ of the metabolome of sensitive $L$. donovani promastigotes, mainly linked to the lipids metabolism (Vincent et al., 2014). On amastigotes it has been described the impairment of the polyamine metabolism from arginine to trypahothione added to an increase in the production of reactive oxygen species (Canuto et al., 2014).

Miltefosine inhibits cytochrome $\mathrm{c}$ in Leishmania donovani promastigotes leading to an impairment of the respiratory chain, reduction in the oxygen consumption rate and mitochondrial depolarization (Luque-Ortega \& Rivas, 2007).

Amphotericin B in its liposomal formulation (AmBisome) is the most effective and frequently used drug for the treatment of visceral leishmaniasis worldwide, as monotherapy or in combinations with pentavalent antimonials or miltefosine (Rama et al., 2015). Clinical trials have demonstrated that patients present better tolerability to liposomal amphotericin B with greater effectiveness of the treatment (Freire et al., 1997). It has demonstrated excellent efficacy against visceral leishmaniasis and has been adopted as firstline regimen in its treatment (Rahman et al., 2017). 
There is a need for new compounds against Leishmania species that are not only potent but also less toxic and more cost effective in humans (Rama et al., 2015).

\section{Praziquantel (PZQ)}

Praziquantel (2-cyclohexylcarbonyl(1,2,3,6,7,11 b)hexahydro-4Hpyrazin(2,1-a)isoquinolin-4-0ne) is a pyrazinoisoquinoline and is the drug of choice to treat several helminthiasis such as schistosomiasis, teniasis, cysticercosis and others. In spite of the extensive studies of its mechanism of action it is still not totally elucidated (Thomas \& Gonnert, 1977; Chai, 2013). It is interesting to highlight that PZQ is active against several flatworms and not nematodes and this occurs because the main target of the drug is a unique gene product which is found only in flatworms (Greenberg, 2005) or this target might be encoded in genes that are transcripted in different structural signatures that do not enable the interaction with PZQ (Greenberg, 2005).

Since the first studies of the PZQ's mechanism of action the tetanic contraction of the musculature and structural damage of the syncytial tegument were described (Andrews, 1985, Greenberg, 2005). These effects lead to exposure of parasite antigens on the worm surface enabling the immunological attack (Greenberg 2005).

Tegumental damage is observed by vacuolization and blebbing in in vitro Schistosoma mansoni. This effect is dose dependent and may be so severe that parts of the parasite are lost (Andrews, 1985; Doenhoff et al., 2008). Both muscle contraction and tegumental damage are $\mathrm{Ca}^{2+}$ - dependent processes as the removal of calcium from the medium blocks these responses (Greenberg, 2005). There are several targets related to calcium homeostasis within the parasite which are voltage-, ligand- and second messenger-gated calcium channels, intracellular calcium release channels and intracellular calcium buffers which alter the intracellular calcium concentrations resulting both in impaired membrane fluidity and in the spastic contracture of the muscle (Greenberg, 2005, Jeziorski \& Greenberg, 2006; Aragon et al., 2009).

Transcriptomic assays that analyzed both sensitive and resistant miracidia and developing adult Schistosoma mansoni determined that susceptibility to PZQ is linked to genes involved in aerobic metabolism and cytosolic calcium regulation (Aragon et al., 2009).

One problem of the PZQ efficacy is that it shows parasite stage and sex dependent differences in susceptibility when used in the schistosomiasis treatment (Greenberg, 2005). The importance of ATP-binding cassette (ABC) multidrug transporters in the praziquantel resistant Schistosoma mansoni strains have been reported. These studies have enabled the determination of the role of these transporters both in drug resistance and in several physiological functions such as excretion and permeability barriers (Greenberg 2014). Also 
transient receptor potential (TRP) channel which is an ion channel related to the pharmacological properties of PZQ in S. mansoni. These channels are essential to transducing sensory signals and in the regulation of the intracellular calcium and therefore are related to sensitivity to PZQ (Bais \& Greenberg 2016).

Nanoformulations of PZQ have been developed as to increase the efficacy of the drug as described in in vivo and in vitro essays in S. mansoni (Kolenyak-Santos et al., 2014) and in the experimental model of cysticercosis (Silva et al., 2016)

\section{Niclosamide}

Niclosamide (5 - chloro - N - (2 - chloro - 4 - nitrophenyl) - 2 - hydroxy - benzamide), is a benzenoid and is indicated to treat intestinal tapeworms. It has a poor absorption and does not reach active concentrations in plasma as neither the drug nor its metabolites have been recovered from the blood or urine, therefore it does not have efficacy against tissue parasites (Pearson \& Hewlett, 1985; Swan, 1999).

Adult worms, not larval stages nor eggs, are killed through an impairment of the oxidative phosphorylation or stimulation of ATPase activity. Parts of the parasites are eliminated with the feces while others are destroyed within the intestine (Poole et al., 1971; Pearson \& Hewlett, 1985).

The most reported use of niclosamide is as moluscicide in order to eliminate the intermediary hosts of Schistosoma sp. In Oncomelania hupensis, the intermediate host of $S$. japonicum, niclosamide induced a significant decrease in the number of mitochondria which presented morphological alterations of their cristae, associated to polarized heterochromatin, decreased number of ribosomes in the rough endoplasmic reticulums, damaged cell structures and organelles, leading to the death of the snails (Xiong et al., 2016). Also molecular analyses performed in Biomphalaria glabrata showed that niclosamide interfered on the transcriptional responses of genes involved in the biotransformation of xenobiotics such as cytochrome P450, glutathione S-transferase, drug transporters, multi-drug resistance protein as efflux transporters and solute linked carrier as influx carriers (Zhang et al., 2015).

Nitazoxanide (NTZ)

NTZ (2-[(5-nitro-1,3-thiazol-2-yl)carbamoyl]phenyl acetate) is a synthetic nitrothiazol-salicylamide derivative. Initially indicated as antiprotozoal agent used against Giardia intestinalis and Cryptosporidium sp is now indicated in the treatment of both intestinal and tissue parasites, whether protozoans, flatworms or nematodes (White, 2004). 
After oral administration it is rapidly hydrolyzed into tizoxanide. However both NTZ and tizoxanide have efficacy against parasites evaluated in in vitro and in vivo essays (Palomares-Alonso et al., 2007).

The biochemical target of NTZ and tizoxanide is the pyruvate ferredoxin oxidoreductase, the enzyme responsible for the decarboxylation of pyruvate into acetyl-CoA (White, 2004; Hoffman et al., 2007). It impairs the tricarboxilic acid cycle as it decreases the acetyl-CoA supply for the cycle to continue, forcing the parasite to use alternative sources of acetyl-CoA such as fatty acids oxidation and proteins catabolism (Isac et al. 2016). Also the excess of pyruvate induces acidosis due to an increase in lactate concentrations which also induces gluconeogenesis (Isac et al., 2016).

\section{Benzimidazoles - albendazole, mebendazole and triclabendazole}

Albendazole (methyl N-[6-(propylsulfanyl)-1H-1,3-benzodiazol2-yl]carbamate), mebendazole (methyl N-(6-benzoyl-1H-1,3-benzodiazol2-yl)carbamate) and triclabendazole (6-chloro-5-(2,3-dichlorophenoxy)-2methylthiobenzimidazole) are indicated in the treatment of both intestinal and tissue flatworms and nematodes (Gottschall, 1990; Lacey, 1990).

The anti-parasitic main mode of action of benzimidazole drugs is to impair the tubulin polymerization into microtubules and therefore disrupting microtubule-based processes (Lacey, 1990; Fairweather \& Boray, 1999). Tissue parasites, such as vascular and interstitial ones, are less sensitive than intestinal ones. Also activity against developing stages is superior to that against adult ones (Lacey, 1988). After the drug activation within the host, usually a sulfoxidation reaction in the liver, the active compound is capable of inducing impairment of $\beta$-tubulin polymerization, perturbation in parasite motility, nutrient uptake, enzyme secretion and glycolytic enzyme activities (Lacey, 1988, Martin et al., 1997).

Biochemical effects are also described in the activity of fumarate reductase and on traditional and alternative energetic pathways both in in vitro and in vivo assays (Lacey, 1988; Vinaud et al., 2007; 2008; 2009; Fraga et al., 2012). Glucose uptake impairment, uncoupling of oxidative phosphorylation, depression of ATP levels, inhibition of transmembrane proton discharge and increase in $\mathrm{Na}^{+}$uptake were also described (Lacey, 1988).

The resistance against benzimidazoles is increasing due to mutations in the tubulin molecule and to increased active cellular efflux of the drug (Gottschall et al., 1990). Therefore the importance of the development of benzimidazole derivatives that present similar efficacy as albendazole but with different targets within the parasite. This is the case of benzimidazole derivatives which target $\alpha$-tubulin subunit of microtubules and not the $\beta$-one. Studies have shown that these derivatives present similar efficacy both in biochemical and in mortality parameters (Hernández-Luiz et al., 2010; Márquez-Navarro et al., 
2013; Fraga et al., 2016; Fraga et al., 2017). Mebendazole, on the other hand, elicits changes in adenine nucleotides, glucose uptake, glycogen depletion and in the respiratory end product (Behm \& Bryant, 1979).

Therefore we conclude that the understanding of the mechanism of action of the different anti-parasitic drugs help to determine how the parasite is killed within the host, how the parasite develops resistance and what can be done to prevent this. Especially when there are so many cases of drug resistance in veterinary helminthes showing the capability of the parasites to remain viable and contaminating the environment (Wolstenholme et al., 2004). It is of paramount importance that these drugs be used correctly and judiciously as to ensure the adequate response.

\section{REFERENCES}

1. Andrews KT, Fisher G, Skinner-Adams TS. Drug repurposing and human parasitic protozoan diseases. Int J Parasitol Drugs Drug Resist 24: 95-111, 2014.

2. Andrews P. Praziquantel: mechanism of anti-schistosomal activity. Pharmac Ther 29: 129156. 1985.

3. Aragon AD, Imani RA, Blackburn VR, Cupit PM, Melman SD, Goronga T, Webb T, Loker ES, Cunningham C. Towards an understanding of the mechanism of action of praziquantel. Mol Biochem Parasitology 164: 57-65, 2009.

4. Aronson N, Herwaldt BL, Libman M, Pearson R, Lopex-Velez R. Weina P, Carvalho EM, Ephros M, Jeronimo S, Magill A. Diagnosis and Treatment of Leishmaniasis: Clinical Practice Guidelines by the Infectious Diseases Society of America (IDSA) and the American Society of Tropical Medicine and Hygiene (ASTMH). Clin Infect Dis 63: 202-264, 2016.

5. Bais S, Greenberg RM. TRP channels in schistosomes. Int J Parasitol Drugs Drug Resist 6: 335-342, 2016.

6. Behm CA, Bryant C. Anthelmintic action - A metabolic approach (a review). Vet Parasitol 5: 39-49, 1979.

7. Benaim B, Garcia CR. Targeting calcium homeostasis as the therapy of Chagas disease and leishmaniasis - a review. Trop Biomed 28: 471-481. 2011.

8. Bergquist R, Utzinger J, Keiser J. Controlling schistosomiasis with praziquantel: How much longer without a viable alternative? Infect Dis Poverty 6: 74, 2017.

9. Buckner FS, Urbina JA. Recent developments in sterol-14-demethylase inhibitors for Chagas Disease. Int J Parasitol Drugs Drug Resist 2: 236-242, 2012.

10. Campo VL, Martins-Teixeira MB, Carvalho I. Trypanosoma cruzi invasion into host cells: a complex molecular targets interplay. Mini Rev Med Chem 16: 1084-1097, 2016.

11. Canuto GAB, Castilho-Martins EA, Tavares MFM, Rivas L, Barbas C, López-Gonzálvez A. Multi-analytical platform metabolomic approach to study miltefosine mechanism of action and resistance in Leishmania. Anal Bioanal Chem 406: 3459-3476, 2014.

12. Chai JY. Praziquantel Treatment in Trematode and Cestode Infections: An Update. Infect Chemother 45: 32-43, 2013.

13. Colley DG, Bustinduy AL, Secor WE, King CH. Human Schistosomiasis. The Lancet 383: 2253-2264, 2014.

14. Docampo R, Moreno SN. Free radical metabolites in the mode of action of chemotherapeutic agents and phagocytic cells on Trypanosoma cruzi. Rev Infect Dis 6: 223-238, 1984. 
15. Doenhoff MJ, Cioli D, Utzinger J. Praziquantel: mechanisms of action, resistance and new derivatives for schistosomiasis. Curr Opin Infect Dis 21: 659-667, 2008.

16. Ebiloma GU, Igoli JO, Katsoulis E, Donachie AM, Eze A, Gray AI, de Koning HP. Bioassayguided isolation of active principles from Nigerian medicinal plants identifies new trypanocides with low toxicity and no cross-resistance to diamidines and arsenicals. J Ethnopharmacol 202: 256-264, 2017.

17. Fairweather I, Boray JC. Fasciolicides: Efficacy, Actions, Resistance and its Management. Vet J 158: 81-112. 1999.

18. Figueirêdo CBM, Nadvorny D, de Medeiros Vieira ACQ, Sobrinho JLS, Neto PJR, Lee PI, de La Roca Soares MF. Enhancement of dissolution rate through eutectic mixture and solid solution of posaconazole and benznidazole. Int J Pharm 525: 32-42, 2017.

19. Fonseca-Berzal C, Palmeiro-Roldán R, Escario JA, Torrado S, Arán VJ, Torrado-Santiago S, Gómez-Barrio A. Novel solid dispersions of benznidazole: preparation, dissolution profile and biological evaluation as alternative antichagasic drug delivery system. Exp Parasitol 149: 8491, 2015.

20. Fraga CM, Costa TL, Bezerra JCB, Lino Junior RS, Vinaud MC. Taenia crassiceps: host treatment alters glycolisis and tricarboxilic acid cycle in cysticerci. Exp Parasitol 130: 146$151,2012$.

21. Fraga CM, Costa TL, Castro AM, Reynoso-Ducoing O, Ambrosio J, Hernández-Campos A, Castillo R, Vinaud MC. Alternative energy production pathways in Taenia crassiceps cysticerci in vitro exposed to a benzimidazole derivative (RCB20). Parasitology 143: 488-493, 2016.

22. Fraga CM, Costa TL, Castro AM, Reynoso-Ducoing O, Ambrosio J, Hernández-Campos A, Castillo, Vinaud MC. A benzimidazole derivative (RCB20) in vitro induces an activation of energetic pathways on Taenia crassiceps (ORF strain) cysticerci. Exp Parasitol 172: 12-17, 2017.

23. Francisco AF, Jayawardhana S, Lewis MD, White KL, Shackleford DM, Chen G, Saunders J, Osuna-Cabello M, Read KD, Charman SA, Chatelain E, Kelly JM. Nitroheterocyclic drugs cure experimental Trypanosoma cruzi infections more effectively in the chronic stage than in the acute stage. Sci Rep 6: 1-11, 2016.

24. Freire M, Badaró F, Avelar ME, Luz K, Nakatani MS, Teixeira R, Martins Netto E, Badaró R. Efficacy and tolerability of liposomal amphotericin B (Ambisome) in the treatment of visceral leishmaniasis in Brazil. Braz J Infect Dis 1: 230-240, 1997.

25. Frezard F, Demicheli C, Ribeiro RR. Pentavalent Antimonials: New Perspectives for Old Drugs. Molecules 14: 2317-2336, 2009.

26. Genetu BA, Debnath A, Mitre E, Huston CD, Laleu B, Leroy D, Blasco B, Campo B, Wells TNC, Willis PA, Sjö P, Van Voorhis WC, Pillai DR. Susceptibility Testing of Medically Important Parasites. Clin Microbiol Rev 30: 647-669, 2017.

27. Gottschall DW, Theodorides Vj, Wang R. The metabolism of benzimidazole anthelmintics. Parasitol Today 6: 115-124, 1990.

28. Greenberg RM. Are $\mathrm{Ca}^{2+}$ channels targets of praziquantel action? Int J Parasitol 32: 1-9, 2005.

29. Greenberg RM. Schistosome ABC multidrug transporters: From pharmacology to physiology. Int J Parasitol Drugs Drug Resist 4: 301-309, 2014.

30. Hernández-Luis F, Hernández-Campos A, Castillo R, Navarrete-Vázquez G, SoriaArteche O, Hernández-Hernández M, Yépez-Mulia, L. Synthesis and biological activity of 2-(trifluoromethyl)-1H-benzimidazole derivatives against some protozoa and Trichinella spiralis. Eur J Med Chem 45: 3135-3141, 2010.

31. Hoffman PS, Sisson G, Croxen MA, Welch K, Harman WD, Cremades N, Morash MG: Antiparasitic drug nitazoxanide inhibits the pyruvate oxidoreductases of Helicobacter pylori, selected anaerobic bacteria and parasites, and Campylobacter jejuni. Antimicrob Agents Chemother 51: 868-876, 2007. 
32. Isac E, Picanço GA, Costa TL, Lima NF, Alves DSMM, Fraga CM, Lino Junior, RS, Vinaud MC. Nitazoxanide induces in vitro metabolic acidosis in Taenia crassiceps cysticerci. Exp Parasitol 171: 17-22, 2016.

33. Jeziorski MC, Greenberg RM. Voltage-gated calcium channel subunits from platyhelminths: Potential role in praziquantel action. Int J Parasitol 36: 625-632, 2006.

34. Kolenyak-Santos F, Garnero C, Oliveira RN, Souza ALR, Chorilli M, Allegretti SM, Longhi MR, Chaud MV, Gremião MPD. Nanostructured Lipid Carriers as a Strategy to Improve the In Vitro Schistosomiasis Activity of Praziquantel. J Nanosci Nanotechnol 14: 1-12, 2014.

35. Lacey E. Mode of action of benzimidazoles. Parasitol Today 6: 112-115, 1990.

36. Lacey, E. The role of the cytoskeletal protein, tubulin, in the mode of action and mechanism of drug resistance to benzimidazoles. Int J Parasitol 18: 885-936, 1988.

37. Luque-Ortega JR, Rivas L. 2007. Miltefosine (hexadecylphosphocholine) inhibits cytochrome c oxidase in Leishmania donovani promastigotes. Antimicrob Agents Chemother 51: 13271332, 2007.

38. Márquez-Navarro A, Pérez-Reyes A, Zepeda-Rodríguez A, Reynoso-Ducoing $\mathrm{O}$, HernándezCampos A, Hernández-Luis F, Castillo R, Yépez-Mulia L, Ambrosio JR. RCB20, an experimental benzimidazole derivative, affects tubulin expression and induces gross anatomical changes in Taenia crassiceps cysticerci. Parasitol Res 112: 2215-2226, 2013.

39. Martin RJ, Robertson AP, Bjorn H. Target sites of anthelmintics. Parasitology 114: 111-124, 1997.

40. Mukherjee S, Mukherjee N, Gayen P, Roy P, Babu SP. Metabolic inhibitors as antiparasitic drugs: pharmacological, biochemical and molecular perspectives. Curr Drug Metab 17: 937970, 2016.

41. Palomares-Alonso F, Piliado JC, Palencia G, Ortiz-Plata A, Jung-Cook H. Efficacy of nitazoxanide, tizoxanide and tizoxanide/albendazole sulphoxide combination against Taenia crassiceps cysts. J Antimicrob Chemother 59: 212-218, 2007.

42. Paris C, Loiseau PM, Bories C, Bréard J. Miltefosine Induces Apoptosis-Like Death in Leishmania donovani Promastigotes. Antimicrob. Agents Chemother 48: 852-859, 2004.

43. Patterson S, Wyllie S. Nitro drugs for the treatment of trypanosomatid diseases: past, present, and future prospects. Trends Parasitol 30: 290-298, 2014.

44. Paucar R, Moreno-Viguri E, Pérez-Silanes S. Challenges in Chagas Disease Drug Discovery: A Review. Curr Med Chem 23: 3154-3170, 2016.

45. Pearson RD, Hewlett EL. Niclosamide Therapy for Tapeworm Infections. Ann Intern Med 102: 550-551, 1985.

46. Polak A, Richle R. Mode of action of the 2-nitroimidazole derivative benznidazole. Ann Trop Med Parasitol 72: 45-54, 1978.

47. Poole JB, Dooley KL, Rollins LD. Efficacy of niclosamide for the removal of tapeworms (Dipylidium caninum and Taenia pisiformis) from dogs. J Am Vet Med Assoc 159: 78-80, 1971.

48. Rahman R, Goyal V, Haque R, Jamil K, Faiz A, Samad R, Ellis S, Balasegaram M, Boer MD, Rijal S, Strub-Wourgaft N, Alves F, Alvar J, Sharma B. Safety and efficacy of short course combination regimens with AmBisome, miltefosine and paromomycin for the treatment of visceral leishmaniasis (VL) in Bangladesh. Plos Negl Trop Dis 11: e0005635, 2017.

49. Rakotomanga M, Blanc S, Gaudin K, Chaminade P, Loiseau PM. Miltefosine Affects Lipid Metabolism in Leishmania donovani Promastigotes. Antimicrob Agents Chemother 51: 14251430, 2007.

50. Rakotomanga M, Saint-Pierre-Chazalet M, Loiseau PM. Alteration of Fatty Acid and Sterol Metabolism in Miltefosine-Resistant Leishmania donovani Promastigotes and Consequences for Drug-Membrane Interactions. Antimicrob Agents Chemother 49: 2677-2686, 2005. 
51. Rama M, Kumar NV, Balaji S. A comprehensive review of patented antileishmanial agentes. Pharm Pat Anal 4: 37-56, 2015.

52. Rivera G, Bocanegra-Garcia V, Ordaz-Pichardo C, Nogueda-Torres B, Monge A. New therapeutic targets for drug design against Trypanosoma cruzi, advances and perspectives. Curr Med Chem 16: 3286-3293, 2009.

53. Serrano-Martin X, Payares G, De Lucca M, Martinez JC, Mendoza-Léon A, Benaim G. Amiodarone and miltefosine act synergistically against Leishmania mexicana and can induce parasitological cure in a murine model of cutaneous leishmaniasis. Antimicrob Agents Chemother 53: 5108-5113, 2009.

54. Silva LD, Arrúa EC, Pereira DA, Fraga CM, Costa TL, Hemphill A, Salomon CJ, Vinaud MC. Elucidating the influence of praziquantel nanosuspensions on the in vivo metabolism of Taenia crassiceps cysticerci. Acta Trop 161: 100-105, 2016.

55. Singh N, Kumar M, Singh RK. Leishmaniasis: current status of available drugs and new potential drug targets. Asian Pac J Trop Med 5: 485-497, 2012.

56. Swan GE. The pharmacology of halogenated salicylanilides and their anthelmintic use in animals. J S Afr Vet Assoc 70: 61-70, 1999.

57. Thomas H, Gonnert R. 1977. The efficacy of praziquantel against cestodes in animals. $Z$ Parasitenkd 52: 117-127, 1977.

58. Trochine A, Creek DJ, Faral-Tello P, Barrett MP, Robello C. Benznidazole Biotransformation and Multiple Targets in Trypanosoma cruzi Revealed by Metabolomics. PLoS Negl Trop Dis 8: e2844, 2014.

59. Urbina JA. Ergosterol biosynthesis and drug development for Chagas disease. Mem Inst Oswaldo Cruz 104: 311-318, 2009.

60. Urbina JA. Specific chemotherapy of Chagas disease: relevance, current limitations and new approaches. Acta Trop 115(Suppl 1): 55-68. 2010.

61. Verma NK, Dey CS. Possible Mechanism of Miltefosine-Mediated Death of Leishmania donovani. Antimicrob Agents Chemother 48: 3010-3015, 2004.

62. Vinaud MC, Ferreira CS, Lino Junior RS, Bezerra JCB. Taenia crassiceps: Energetic and respiratory metabolism from cysticerci exposed to praziquantel and albendazole in vitro. Exp Parasitol 120: 221-226, 2008.

63. Vinaud MC, Ferreira CS, Lino Junior RS, Bezerra JCB. Taenia crassiceps: fatty acids oxidation and alternative energy source in in vitro cysticerci exposed to anthelminthic drugs. Exp Parasitol 122: 208-211, 2009.

64. Vinaud MC, Lino Junior RS, Bezerra JCB. Taenia crassiceps organic acids detected in cysticerci. Exp Parasitol 116: 335-339, 2007.

65. Vincent IM, Weidt S, Rivas L, Burgess K, Smith TK, Ouellette M. Untargeted metabolomic analysis of miltefosine action in Leishmania infantum reveals changes to the internal lipid metabolism. Int J Parasitol Drugs Drug Resist 4: 20-27, 2014.

66. Walker J, Saravia NG. Inhibition of Leishmania donovani promastigote DNA topoisomerase I and human monocyte DNA topoisomerases I and II by antimonial drugs and classical antitopoisomerase agents. $J$ Parasitol 90: 1155-1162, 2004.

67. White CA JR. Nitazoxanide: a new broad spectrum antiparasitic agent. Expert Rev Anti Infect Ther 2: 43-49, 2004.

68. World Health Organization. Neglected diseases. 2017. http://www.who.int/neglected_diseases/ diseases/summary/en/ accessed in 17/04/2017.

69. World Health Organization. Schistosomiasis and soiltransmitted helminthiases: number of people treated in 2015. Nos. 49/50, 2016, 91, 585-600 http://www.who.int/wer 
70. Wyllie S, Cunningham ML, Fairlamb AH. Dual action of antimonial drugs on thiol redox metabolism in the human pathogen Leishmania donovani. J Biol Chem 279: 39925-39932, 2004.

71. Wolstenholme AJ, Fairweather I, Prichard R, von Samson-Himmelstjerna G, Sangster NC. Drug resistance in veterinary helminths. Trends Parasitol 20: 469-476, 2004.

72. Xiong T, Zhao QP, Xu XJ, Liu R, Jiang MS, Dong HF. Morphological and enzymatical observations in Oncomelania hupensis after molluscicide treatment: implication for future molluscicide development. Parasitol Res 115: 4139-4152, 2016.

73. Zhang S-M, Buddenborg SK, Adema CM, Sullivan JT, Loker ES Altered Gene Expression in the Schistosome-Transmitting Snail Biomphalaria glabrata following Exposure to Niclosamide, the Active Ingredient in the Widely Used Molluscicide Bayluscide. PLoS Negl Trop Dis 9: e0004131, 2015. 